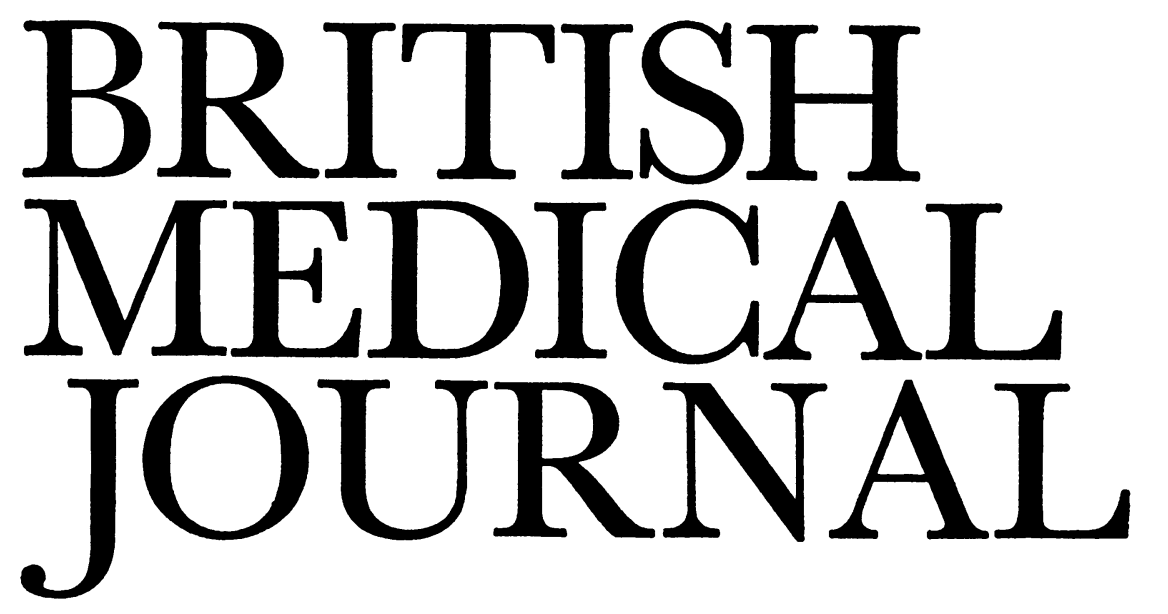

LONDON SATURDAY 19 MAY 1973

\title{
The Odds on Getting a Coronary
}

One of the chief activities of research epidemiologists in recent decades has been a systematic quest for the "causes" of the chronic degenerative diseases. The quest has never been easy, and sometimes has been very difficult, for at least two reasons. Firstly, unlike most acutely infectious conditions, the time elapsing between exposure to a "cause" and the detection of consequent changes in structure and metabolism can be many years. Secondly, most common non-infectious disease is the result of a complex interaction between many factors-a "web of causation." 1 The more factors that are indicted, the more reluctant the epidemiologist has become to use the word "cause" for any of them, and so he has coined the term "risk factor." When a person is exposed to a risk factor, the risk (or probability) he will get the disease under consideration is increased.

The risk can be expressed in several ways. ${ }^{1}$ Conceptually the simplest is to state the chances that a person with certain characteristics will develop a disease in a given period of time. For instance in Framingham, Massachusetts, 41 of 286 men with serum cholesterol levels in excess of $260 \mathrm{mg} / 100$ $\mathrm{ml}$ developed coronary heart disease in the first six years of the study. Thus, other things being equal, the probability of any one of them developing a coronary over that period of time is $41 / 286$, which can be expressed as 0.14 or 1 in 7.2 It would obviously be of great value to a doctor if, with any degree of accuracy, he could assign such a probability to a patient. So far this has not been possible for the very good reason that other things are not equal.

In $1962 \mathrm{~J}$. Cornfield ${ }^{2}$ used data from Framingham to show that blood pressure and serum cholesterol were risk factors for coronary heart disease which were independent and cumulative. That is to say, the risk of developing coronary heart disease was greater if the blood pressure and serum cholesterol were both raised than if one was raised and the other was not. This observation was confirmed in Britain by J. N. Morris and his co-workers. ${ }^{3}$ Thus the doctor in his surgery would be able to calculate the risk his patient ran of getting a coronary attack more accurately if he took blood pressure as well as serum cholesterol into account. Other pieces of information that might help are the age and sex of the patient, and perhaps information about his smoking habits, his physical activity, and his weight.

The statistical approach to the Framingham ${ }^{2}$ and the Lon- don $^{3}$ studies was similar and based on the discriminant function analysis which was first developed by $\mathbf{R}$. A. Fisher, ${ }^{4}$ though Cornfield used it in a modified form. ${ }^{25}$ Cornfield's modification has now been applied with interesting results by Ancel Keys and colleagues together with a group from five European countries. ${ }^{6}$ The risk factors which interested them were age, blood pressure, serum cholesterol, body bulk, tobacco smoked, and physical activity. They found that the first three of these in combination allowed the probability of an American railwayman developing coronary heart disease to be calculated with considerable accuracy. The accuracy was increased marginally by the inclusion of information about tobacco consumption, but consideration of body bulk or physical activity did not improve the estimates. This confirmed previous findings. ${ }^{25}$ However, they went on to show that the weighting factors that had been derived from the study of the railwaymen when applied to data collected by other workers were highly effective for calculating the probability of getting coronary heart disease in Chicago, Massachusetts, and New York. They therefore concluded that so far as the United States is concerned a doctor who knows a man's "age, blood pressure, serum cholesterol, and smoking, can enter those numbers into a multiple logistic equation, together with the constant and coefficients and calculate his probability of developing CHD in five years."6 They go on to say that the calculation is exceedingly simple with a desk computer. Indeed our reader may be assured that it is much simpler than that recently described in these pages for the estimation of blood gases. ${ }^{7}$ Another possibility, which they do not suggest, is that tables could be constructed which would permit probabilities to be read off.

A second important finding in this paper 6 is that the weighting factors which seemed to be so widely applicable in the United States did not prove so good at assigning probability of getting a coronary attack to the men who had been studied in Europe. The authors suggest that the most likely explanation for the difference is that an unidentified risk factor has an important role in the genesis of the disease in Europe but not in America, even though their data confirmed the known fact that the incidence of the disease is higher in the latter. They state that their survey techniques were identical on both continents. Independent evidence that there are differences between the nature of coronary heart disease 
in Europe and in America comes from another recent study, which showed that the prevalence of cardiac pain was twice as high among men in Marion Country, West Virginia, as in Stavely, Derbyshire. ${ }^{8}$

The evidence that physical inertia at work is important has been growing through the years, ${ }^{9-12}$ and to this have been added studies which indicate that physical inertia during leisure hours is also important. ${ }^{1314}$ It does not require elaborate epidemiological research to show that there is a close interrelationship between physical inertia, body bulk, and consumption of food, so that these secondary risk factors must act through the three important primary risk factorsage, blood pressure, and serum cholesterol-the three which apparently can effectively be used to determine who will get a coronary attack. This case has already been argued. ${ }^{3} 15$

But what Keys and his group are now suggesting is that after 30 years of concentrated effort on both sides of the Atlantic there is still another primary risk factor to coronary heart disease which has gone undetected. On this point further evidence is needed, but the practical importance of their work is incontestable. If the studies which are at present underway are successful in showing that the incidence of coronary attacks can be reduced by programmes which control blood pressure and serum lipid levels, we shall want to identify the high-risk individuals as accurately as we can.

${ }^{1}$ MacMahon, B., and Pugh, T. F., Epidemiology: Principles and Methods. Boston, Mass., Little, Brown and Company, 1970.

2 Cornfield, J., Federation Proceedings, 1962, 21, 58.

3 Morris, J. N., Kagan, A., Pattison, D. C., Gardner, M. J., and Raffle, P. A. B., Lancet, 1966, 2, 553.

4 Fisher, R. A., Annals of Eugenics, 1936, 7, 179.

5 Truett, J., Cornfield, J., and Kannell, W., Fournal of Chronic Diseases, $1967,20,511$.

- Keys, A., et al., Circulation, 1972, 45, 815.

7 Grogono, A. W., British Medical fournal, 1973, 1, 381.

8 Grogono, A. W., British Medical fournal, 1973, 1, 381.

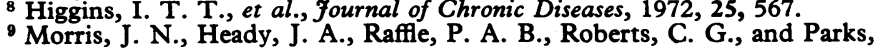
J. W., Lancet, 1953, 2, 1053.

10 Taylor, H. L., et al., American Fournal of Public Health, 1962, 52, 1697.

11 Kahn, H. A., American fournal of Public Health, 1963, 53, 1058.

12 Paffenbarger, R. S., Gima, A. S., Laughlin, M. E., and Black, R. A., American fournal of Public Health, 1971, 61, 1362.

13 Paffenbarger, R. S., Wolf, P. A., Notkin, J., and Thorne, M. C., American Fournal of Epidemiology, 1966, 83, 314.

14 Morris, J. N., et al., Lancet, 1973, 1, 333.

15 Acheson, R. M., Yale Fournal of Biology and Medicine, 1962, 35, 143.

\section{The Medical Society of London}

Founded in 1773, the Medical Society of London celebrates its 200th Anniversary this month. Its founder, Dr. John Coakley Lettsom, F.R.S. (see also page 431), was born in the West Indies - said to be one of seven pairs of twins-in 1744 , and practised as a highly successful London physician during a time when there were bitter rivalries and strife in the medical world and appalling conditions among the sick poor. The state of the prisons and the lunatic asylums gave evidence of the deplorable standard of health, nutrition, and hygiene of the people in the cities. There was little cooperation-often not even association-between the apothecaries, surgeons, and physicians, and large numbers of untrained and uneducated people carried on a lucrative trade as "empirics" or quacks. There was little chance for even the trained doctor to learn new methods or hear of work done in other countries.

To try to overcome some of these defects Lettsom, then still only 29 , founded a society with the purpose of uniting the three branches of the profession so that they could meet in their own house, exchange medical news, find a library of books to read, make friendships, and "advance science." At first he called his society "The Society in Crane Court," and its members met in taverns- 30 physicians, 30 apothecaries, and 30 surgeons. Later he presented the Society with its own building, No. 3 Bolt Court, off Fleet Street. There it held its fortnightly meetings, in the same Court as the Royal Society, until 1850, when it moved-as fashionable society was moving-out of the city to the West End, finally settling in its present building, Lettsom House, 11 Chandos Street, in 1873. It was the first "mixed" medical society to be formed in England, though there had been medical societies in Edinburgh since 1731, and the Physical Society at Guy's Hospital had begun in 1771 .

For 200 years the Medical Society of London has kept an unbroken record of regular lectures and discussions on every aspect of medicine and surgery and has avoided any specialization. Its list of past presidents and orators is an impressive one, and includes distinguished leaders in many fields of medicine. One of its earliest Fellows was Edward Jenner, and the second lecture given to the society by Lettsom was "In Defence of Vaccination."

It was through Lettsom's friendship with Dr. Benjamin Waterhouse, professor of medicine at the newly founded Harvard Medical School, that supplies of vaccine were sent to North America, where Jefferson supported its general acceptance, and it was adopted throughout the country. It was another close friend of Lettsom's, a Quaker from the West Indies and a corresponding member of the Medical Society, Dr. William Thornton (1761-1828), who besides practising medicine was also a skilful architect and built the most famous building in America, the Capitol and President's House in Washington.

In 1805 William Saunders, Astley Cooper, and others left the Society and formed a new medical and chirurgical society which later merged with other societies until in 1907 it became the Royal Society of Medicine.

The story of Lettsom's life and career has been well told, ${ }^{12}$ and his varied achievements clearly show what an exceptional man he was. An immense capacity for work, a sincere wish to help those in need, considerable skill in diagnosis, with a humane and practical approach to medical treatment, were linked with a readiness to question existing ideas. It was he who deserves much of the credit for letting the sunlight and fresh air into dark and insanitary houses, closed-in wards, and airless buildings. It was largely due to his efforts that the Sea-bathing Hospital at Margate was built in 1791. Treatment by sea bathing, especially after George III's visit to Weymouth, was becoming popular, and Lettsom was an enthusiastic supporter of the new fashion, making visits to his Margate hospital to see his sick-poor patients transported from London by sailing boats. He was concerned with the beginnings of the Royal Humane Society and new methods of resuscitation of the apparently drowned.

Postgraduate training has advanced so rapidly during the last two decades that it may well be asked whether there is still a place for such a society as the Medical Society of London in present-day conditions. To this there can be a clear answer that with the right aims and its present beautiful house in Chandos Street there surely is. The Society has wisely sent most of its valuable-and in some respects unique-library to the Wellcome Historical Library, where its rare books can be kept in ideal conditions, readily avail- 